\title{
15 The mining industry: the journey from impunity to consent
}

\author{
Raymond Offenheiser
}

For millennia, humans have valued metals and precious stones, committed heinous crimes to obtain them, traveled great distances to trade them, and created and sustained empires based on their real or imputed value. Spanish conquistadors took an Incan emperor hostage so he would reveal gold sources. Many lives over centuries have been sacrificed at mines, often brutally and without accountability. Until the late twentieth century, mining required large numbers of laborers working at great risk for paltry wages to extract precious metals and ores.

Happily, this is not the world we live in today. As one mining executive remarked to me casually: "There is no backyard on earth today where we can dig a hole without the world knowing about it in 24 hours." This is not to say there are no longer any bad actors, horrific working conditions, or human rights violations. It's still hard to find any place on earth where there is not some conflict over mining. Moreover, we live in a globalized world with exploding demand for minerals. It's estimated that some ninety metal and mineral commodities are required to power the global economy (US Geological Survey n.d.).

Those interested in engaging mining companies in dialogue and driving significant change need to recognize that a lot of normative progress has been made in a relatively short period of time. Today there are dozens of voluntary normative frameworks focused on ethical issues, human rights, specific commodities, industry operational practices (tailings dams), transparency and taxation, and certification standards (World Economic Forum and Global Agenda Council on the Future of Metals and Mining 2015). These new frameworks influence the industry and create tools for Catholic organizations and others to scrutinize and propose changes to industry policies and practices, and to advance bold regulatory reform.

While progress in realizing rights and justice on some fronts has been made, the normative frameworks for extraction need to be refined and taken from C-suites to mine sites, through supply chains for full implementation, and, finally, to legislatures. Catholic and other civil society actors should build upon these norms and incorporate them into their 


\section{Raymond Offenheiser}

strategies as they push the industry toward greater sustainability, peace, and integral human development.

\section{Ethics and mining}

Mining presents a vast array of ethical questions at multiple levels, but the idea that there should be an ethics for mining is relatively new. While norms for agriculture, forestry, and fisheries have been included in international environmental and development summits and natural resource policy documents since the early 1970s, mining was somehow overlooked. Not until the late 1990s was consideration given to the environmental, and later, the social, and economic impacts of mining. Mining is foundational to modern life and, as George Orwell described it, part of the "metabolism" of civilization. Yet there has been little scrutiny until recently of the complex issues of conflict, poverty, and injustice that surround it, to say nothing of its growing strategic importance and long-term sustainability.

In Laudato Si', Pope Francis examines the moral challenges posed by mining on a planet with limited natural resources and under pressure from a global climate crisis. He offers considerations for how unfettered growth and a global consumer culture affect the calculus of costs and benefits in industries like mining. He questions how much the prevailing consumerist culture that depends on mining is itself in need of drastic change. In his development of the idea of integral ecology, he delivers a mandate for Catholic leaders and activists to tie their work to the machinations of the globalized economy, the consumerism that drives it, and its immense consequences for "our common home." Mining is squarely within that purview.

Despite these ethical concerns, can we live without mining metals and minerals or are they essential for the survival and advancement of civilization? Can we live without steel girders that support our modern buildings, bridges, and infrastructure, or lithium for batteries that electrify our homes, or copper that supports our electrical grids? There are 62 unique and irreplaceable metals in every cellphone. Each one must be mined somewhere at some cost to environment and society. Is securing those metals a cost we can and must bear? While the mining industry is exploring the development of synthetic minerals and mining the moon, it is unlikely these efforts will be sufficient to address the exploding demand for critical minerals needed for information technology, mass communication, and energy any time soon.

There is certainly a case to be made for challenging extractive industries and their wholesale and retail customers to embrace responsible stewardship of the planet and envision a world in which extraction is limited to the essential, but how do we define essential? Do we devalue precious stones and jewelry? Do we impose regulatory limitations mining lowgrade mineral deposits for certain precious stones and metals? Do we 
increase investment in the search for synthetic minerals that would reduce environmentally destructive extraction? Such efforts would require major changes in public taste and values but are goals that should be under consideration. These kinds of questions point toward the complexities that lie before us in trying to limit and regulate the scale and impact of the mining industry. We need it, yet it will continue to be a dirty business riddled with ethical dilemmas.

But to tackle these ethical questions and be effective in addressing them, Catholic peace, human rights, and development activists will need to become more knowledgeable about the inner workings of this industry: its business ecosystem, its profitability, its strategic priorities, its internal incentives and policies, its technical complexities, and its financial and operational vulnerabilities. They will need to also reckon with the unique contributions the mining industry makes to society as they respond to the pope's critique of consumerist culture and an economy that prioritizes growth over other values.

\section{Understanding the mining mindset}

In seeking to transform the mining industry, it is critical to understand its worldview, values, and culture. While mining technology has improved over the centuries, it is still fundamentally about digging large holes in the earth to extract value from a very small quantity of minerals. Today, ore grades have declined globally, so companies must move ever-increasing amounts of earth to extract very little real value. One gold wedding band may require the removal and processing of thirty tons of earth.

The industry is largely led by mining engineers and geologists who are trained to determine the smartest way to extract the maximum amount of mineral value from a discrete piece of ground. They are single-minded about this task. What matters to them is what is in the ground inside the fence where they operate. They are linear thinkers and they have little regard for how what they are doing inside the fence might affect those living outside the fence. These geologists and engineers define the culture of the mining industry. Today, however, this culture is under increasing pressure to change in fundamental ways.

For many centuries, mining was able to exploit surplus land and labor with little regard for safety, human rights, wages, or ecological or community impacts. But companies can no longer treat environmental damage, injury, or death as incidental costs of doing business. Having suffered major legal and financial setbacks over the last fifty years, companies are highly sensitive and proactive about safe working conditions. Serious environmental catastrophes like the Samarco tailings dam collapse in Brazil in 2015 have demonstrated to executives the scale of liability possible from lax management of critical risks. In perhaps an equally dramatic example, as detailed by Andres McKinley in this book, the perceived downstream 


\section{Raymond Offenheiser}

risks of water shortages to agriculturalists led El Salvador's Congress to ban all large mining projects in the country, the first nation in the world to take such drastic legal action. Events like these and increasing investor scrutiny of environmental, social, and governance policies and practices have forced particularly the largest companies to rethink their business models and incorporate new ethical and performance policies. These new standards represent a real shift by companies to incorporate ethics guidelines for what they will commit to do "outside the fence."

The industry's first efforts were to embrace broad principles of corporate social responsibility while treating challenges as a public relations matter. They later reluctantly embraced the concept of social license as a recognition that public relations would not suffice and that they had to engage communities in new ways. The initial ways in which companies tried to acquire social license were perceived by communities and civil society as short-term transactional approaches that did not address long-term development interests and justice concerns. But in the late 1990s, leading companies, or Majors, ${ }^{1}$ began to engage a broad spectrum of non-industry stakeholders. In the early 2000s, the Majors created the International Council on Mining and Metals (ICMM) as a joint initiative to address a wide array of shared concerns, such as sustainability, indigenous rights, waste management, and mine closure. To join, companies had to pledge to implement the ICMM Ten Principles, which give industry guidance across ten areas of ethical consideration: ethical corporate governance; sustainability-driven decision-making; human rights; stakeholder-sensitive risk management; worker health and safety; environmental performance; conservation of biodiversity; support for responsible metal and mineral disposal, reuse, and recycling; social performance; and stakeholder engagement (International Council of Mining and Metals n.d.a). As time has gone on, expectations have been raised and additional dimensions like gender and equitable distribution of costs and benefits have been included.

Mining companies have to modernize, not only technologically but in terms of values and approach. They need to hire outside their traditional circles of geologists and engineers and incorporate personnel who bring ethical, environmental, economic, social, and political perspectives aligned with sustainability and human rights. At the same time, the promise of the reforms achieved thus far will not be fully realized without significant and continuing pressure from key investors, consumers, peacebuilders, and human rights activists. The moral authority and influence of the Catholic Church give it a prominent role in this regard.

\section{A critical perspective on normative progress}

It is important to recognize that most of what has been achieved is in the form of ethical frameworks and voluntary principles, or soft law. Very little has been achieved in terms of transforming soft law into hard 
law-i.e., legislation and regulation. The consequence of this is uneven performance from the industry, and likely the need over time to transition some voluntary standards to hard law. Industry leaders understand this and are the first movers in adoption and implementation. They would prefer to move quickly on controversial issues and stay ahead of aggressive regulatory campaigns where they feel voluntary principles would both suffice and afford them greater flexibility in their responses. Secondtier companies, or Juniors, have been less responsive than the Majors, who are all ICMM members.

While not always the ideal outcome for mining reform advocates, this proliferation of normative frameworks is generating policy debate within corporate board rooms and trade associations, which represents enormous progress over where things were even twenty years ago. It is useful to critically review progress across different areas that have been sources of conflict.

\section{Environmental impact}

Environmental impacts are one of the oldest and most common sources of conflict between companies and communities. Hence, it is no surprise that environmental impact has been the area on which companies have moved most readily. There are several reasons for this. While environmentalism began earlier in industrialized countries, by the early 1990s environmental movements were growing in countries across the world. The Rio Climate Summit brought together these national movements and enabled them to forge common bonds. Governments were soon establishing environmental ministries and requiring environmental impact assessments, and investor groups were taking note and incorporating environmental principles into their assessment criteria. Another reason for the readiness of companies to respond to environmental concerns is to avoid expensive legal fights and reputational damage. The famous case of the Texaco oil spill in the Ecuadorian Amazon that dragged on over two decades in US and Ecuadorian courts is well-known within the industry. There have been other cases as well, perhaps less publicized, but no less costly.

Companies have gotten very sophisticated about their environmental management capabilities and have incorporated environmental engineers into their teams to monitor a variety of potential impacts, including chemical pollutants, dust, tailings spills, drainage, water quality, and carbon footprint. In the most sophisticated cases, they are even monitoring regional biodiversity and conservation far beyond their mine sites. Given the scientific base for environmental monitoring, it has been relatively easy to fit environmental scientists into their existing staff configurations. The larger challenge has been to get company culture to recognize that there may be situations when environmental conditions are not favorable to extraction due, for example, to regional watersheds or sub-surface water systems. 


\section{Raymond Offenheiser}

At the country level, environmental impact assessments are done by the interested company and not by independent bodies. Depending on the national context, companies may understate risks knowing that governments will not conduct secondary reviews. In other cases, governments wanting the revenue will simply overlook any perceived risk and then not enforce or penalize companies when there are significant impacts on communities and public health. Environmental impacts are often felt from the earliest days of a project and for generations beyond its closure. While progress has been made in the upfront assessment of environmental risk, there is still a great deal to be done by both governments and companies in determining who will pay for downstream impacts over the duration of a project and beyond. The most sophisticated companies are doing lifecycle cost assessments and assuming in perpetuity liability for certain kinds of projects. But many governments and community groups lack the sophistication to do this kind of lifecycle assessment, build appropriate costs and conditions into project approvals and long-term contracts, or pressure companies not acting with good will to do so.

Companies and governments have made significant progress on environmental concerns, but performance across the industry is still uneven and requires independent monitoring. The industry will improve its performance only in response to citizen action and more effective government regulation and enforcement. Advocates interested in integral human development and peacebuilding would be wise to engage with communities, governments, and environmentalists in the early stages of project development in order to address the knowledge asymmetry and bring the best science and negotiating skills to contract negotiations with companies on behalf of affected communities.

\section{Indigenous rights and other human rights}

Human rights is an area fraught with the potential for violent conflict and requires ongoing oversight and vigilance. Unlike with environmental issues, mining companies lack competency in this field and yet recognize it is an area of considerable risk and vulnerability.

As illustrated in the chapter on Peru by José Bayardo Chata Pacoricona, indigenous rights violations continue to be one of the principal areas of contention and conflict between companies and communities. Many mining projects are located on lands titled under legacy treaty arrangements to indigenous populations. They may be aboriginal peoples in Australia, low caste tribal groups in India, or native populations in the depths of the Amazon. Quite often, these lands have powerful cultural importance. In many cases, governments have ceded indigenous communities the right to surface lands while retaining the rights to the sub-soil. Conflicts ensue when the state grants exploitation rights to extractive industries that then must open vast tracts of surface land to access their claims and begin extraction. 
Very often, these deals are consummated without any consultation with the indigenous population. Once the first access road is opened up, colonists quickly follow, staking claims to indigenous territory. Governments simply look the other way and ignore any claims by indigenous communities to protect their territorial rights.

In the past, governments would simply force access for the companies with police action. Today, this kind of frontal assault on the rights of indigenous people would be actively resisted, leading to violence and likely the killing of indigenous peoples. Companies are now taking entirely different approaches. In Canada, where the government has strengthened the rights of First Nations over their traditional lands, tribes are negotiating equity partnerships over mining properties. In Australia, companies are negotiating collaborative agreements with aboriginal owners over access, water management, and, even in some cases, restoration and management of traditional lands. BHP, the largest mining company in the world, recently announced its support for proposals to amend the Australian constitution to recognize the territorial rights of traditional owners (Australian Associated Press 2019).

While these are welcome steps toward wider recognition of indigenous rights, there are many other places where indigenous rights are still widely abused. Governments often find it challenging to balance the collective ownership rights and cultural practices of native peoples with their desire to promote the economic ambitions of a major corporation. In Peru, a recent administration sought to pass legislation undermining the concept of collective title. In African nations, collective lands are often under the control of tribal chiefs who will bow to government pressure and make deals with private companies with no consultation with their tribal constituency. A government's lack of respect for collective ownership either undermines the entire historic titling of lands to native peoples or forces a tribe to parcel out lands to their members so that the individuals might more easily be forced to forfeit ownership or sell to interested commercial entities. While this would all be technically legal, we are likely to continue to see human rights challenges where indigenous collective rights of ownership are at odds with the capitalist impulse to commodify land in service to economic interests.

Apart from conflicts over indigenous rights, it is not uncommon for local communities to experience violent confrontations with security services contracted by companies to patrol and defend the company's property boundaries. And it is also not uncommon for those security forces to act with impunity due to the backing of government powers. A representative case comes from a nickel mine outside El Estor, Izabal, Guatemala. The mine was operated by the Canadian firm Hudbay Minerals. The mine's security forces perpetrated years of violence against the surrounding community, including assassination, rape, forced displacement, and criminalization of protest. In 2009, community leader Adolfo Ich was killed, setting off a series of court cases in Guatemala and 


\section{Raymond Offenheiser}

Canada (Russell 2019). The chief of security who killed Ich was finally convicted in January of 2021.

When confronted with violations of human rights or financial malfeasance, companies prefer a soft-law solution in the form of voluntary principles, such as the widely-accepted Voluntary Principles on Security and Human Rights (Voluntary Principles Initiative n.d.). Such a solution shields companies from real liability and leaves room for them to manipulate how their performance is gauged. This is not to say that voluntary frameworks like these are of little value. Their mere existence forces companies to raise human rights to a top-level priority with their operational managers, challenging them to carefully screen and train all security personnel to ensure compliance with human rights principles. Some companies now routinely hire independent human rights lawyers to evaluate their human rights risks and recommend policy and practice reforms. In one notable case, Newmont Mining walked away from its Conga Project in Cajamarca, Peru, a multi-billion-dollar gold and copper mine, after various violent incidents and protracted conflicts with local citizen groups and the regional government.

Companies like Newmont recognize that absent community consent, they risk committing serious human rights violations and then facing lengthy prosecution and costly court rulings. Companies have come to realize that they must find new and constructive ways to engage. Free, prior, and informed consent and social license have accordingly become mainstreamed parts of most mining companies' basic operations, and they are perhaps the most powerful normative tools available to defend indigenous land claims and the rights of local communities.

\section{Free, prior, and informed consent and social license to operate}

Free, prior, and informed consent (FPIC) is a response to companies securing mining rights from governments with little or no consultation with local communities. The goal of FPIC is to give a community the opportunity to conduct a public referendum on whether it endorses proposed mining in its region.

The first public use of this concept was in Tambogrande, Peru, a small town in a river valley on the Peruvian north coast whose economy is entirely dependent on irrigated agriculture. The community was concerned that mining operations would consume too much water upstream and undermine their agriculture downstream. The town organized a referendum to test public sentiment and the vote was $96 \%$ against the mine. The Peruvian government accepted the community's decision and Manhattan Minerals had to abandon the project. This decision had a profound effect on the mining industry. Prior to that case, industry presumed that a license to explore was implicitly a license to exploit. After the Peru decision, social license was no longer an abstract concept, but something requiring formal 
approval by host communities. This was an unexpected and revolutionary turn of events.

There have been few other referenda like the one in Tambogrande, but companies are wary and on notice. Their response has been varied. Some companies, largely Majors, have in principle incorporated the idea of FPIC in their policies and public statements. Others have not gone that far. Even in cases when the community right to FPIC is acknowledged, the company preference is to interpret the process as free, prior, and informed consultation rather than consent, in keeping with the accepted language of the ICMM (n.d.b). That word change can prevent FPIC from having real force, keeping communities from having the right to say "no" to a project and making the consultation frequently amount to nothing more than showy formality. The notion that communities can undermine substantial corporate investment through a community-led referendum is still an idea most companies are not ready to fully endorse. Companies would prefer to avoid a referendum and do their own assessment of community support before ever putting a shovel in the ground. Especially when backed by governments, FPIC has clearly given communities a powerful normative tool that companies feel obligated to observe. And while FPIC is still often undermined or watered down, it has done enough to make the industry shift to a more robust focus on acquiring genuine social license to operate in local communities.

Securing social license to operate is one of the most important issues for company executives today. When a company invests large tranches of capital into a particular project, it needs to exploit that mine for as much as thirty years before it can realize a significant profit. Companies used to operate with little concern for the impact on the wider community. However, the Minahasa Raya mine experience in Indonesia, in which Newmont Mining had multiple executives jailed on charges of dumping tailings into a nearby bay, and the Cajamarca case of mercury poisoning in a rural Peruvian village taught companies that such incidents seriously undermine public trust and can lead to complex problems that stall production for months.

In its earliest use, social license posed the simple question to company personnel: What is it going to cost to buy off community dissent so that we can proceed with operations? Over time, companies realized that their approach to community consultation was flawed in several respects. The personnel charged with managing community relations were simply not trained or equipped to take on this role. They did not understand complex community dynamics; were impatient and looking for a quick fix; and were poor tacticians and negotiators. They generally favored a very narrow and advantaged segment of the community and excluded other, more critical voices. They tried to offer small contributions for the construction or improvement of a school or clinic that was disproportionate to the scale of need, expectations of communities, and profit realized by 
the company. Many company leaders recognized that they needed to recruit and develop new personnel with the skills and competencies to work successfully outside the fence.

The pursuit of social license, with all the flaws described, remains the strategy of many companies. However, others have gone further and embraced the idea of "shared social value" (Porter and Kramer 2001). Shared social value assumes that the values of the company and society should align. With every new project, a company should appreciate the broad societal value it might bring to the communities directly or indirectly impacted by its operations. Discussions on social license should take place throughout the entire lifecycle of a mine. On its face, shared social value is potentially a dramatic leap forward from the highly transactional, myopic, one-and-done, and self-serving notion of social license and the preferred soft consultative version of FPIC. In theory, it signals a company's embrace of a larger regional development vision in its own planning and investments. In practice, this could mean engaging in elaborate multi-stakeholder planning for how mining operations contribute to regional development priorities. It could mean mine lifecycle planning with local and regional communities to reach some consensus on a post-extraction vision for the region and its resources. It could mean sizeable investments in regional infrastructure and services outside the confines of the mine. It could mean joining with local public officials to advocate with the national government for greater transparency about mining revenues and more strategic investment of these revenues in the region. It could mean becoming a true development partner with a region and setting a model for what sustainable mining might look like.

Shared social value is a new business narrative that takes us beyond FPIC and social license to a higher level of awareness within corporate culture of the responsibilities that should come with operating an ethical enterprise. At a time when public trust in institutions, and particularly multinational corporations, is at an all-time low, smart CEOs see shared social value as perhaps the only way companies may secure and sustain trust and be part of building a more humane and just form of capitalism. By embracing the shared value narrative, the company still seeks to play a major role in determining how value is defined. While conceding the legitimacy of the ethical question, the company retains control of the value narrative. But this is a pressure point where peacebuilders and activists can push for more substantial change.

\section{Fiscal justice: transparency and taxation}

For much of their history, extractive industries have enjoyed the advantage of relative obscurity. They operate in remote locations the public seldom sees. Their brands are unknown and their products sold business-tobusiness. It is only within the last twenty-five years that economists have 
blamed extractive industries for the "resource curse," environmentalists for egregious dumping of waste products, and human rights activists for gross human rights violations. As citizens are demanding much greater transparency and accountability from their leaders and institutions, mining, given its sizable economic footprint, has become a major target of scrutiny.

After a 2003 World Bank report called for an end to investments in coal and other major extractive projects, UK Prime Minister Tony Blair spearheaded the Extractive Industry Transparency Initiative (EITI). This initiative required governments and companies to subscribe publicly to its Ten Principles that included transparent corporate governance, human rights, sustainability, sound risk management, zero harm on worksites, and continuous environmental improvement in order to receive certification and become an EITI member. ${ }^{2}$ Reviews of this initiative are at best mixed, with many countries embedding the principles in policy but failing to monitor implementation. Nonetheless, this initiative has offered advocates a forum in which to pressure both governments and companies on failed performance.

Building on the momentum of the EITI process, one of the most significant accomplishments of the last twenty years was the United States' passage of Section 1504 of the Wall Street Reform Act in 2010 (HR 4173, 111th Cong. (2010)). This tiny amendment was added to a massive financial reform law, despite strong opposition, especially from oil companies. It requires that all oil, gas, and mining companies publicly traded on the US Stock Exchange publicly report their financial transactions with any government in the world down to the project level. Since $95 \%$ of extractive industries globally are traded on the NY Stock Exchange, it has almost global coverage. Soon after, similar pieces of legislation were passed in the UK, the EU, Norway, and Canada. Companies soon realized that it was no longer possible to avoid these reporting requirements and quickly adjusted their public reporting to reflect the full scale of their financial dealings with countries around the world. Overnight, billions of dollars of royalties, profit, and miscellaneous financial transactions were made public. It was now possible for citizen groups across the world to actually see the level of revenue being received in both taxes and royalties from large international mining companies and to ask probing questions of their governments about how those funds were being allocated to national budgets, opening up more opportunity to recognize corruption. For companies that paid taxes to their host governments, the disclosures shifted attention to the governments' misappropriation of funds. Bolivia is a case in point. It renegotiated its contracts with many extractive firms and now enjoys massive government surpluses that it can dedicate to its own development.

A corollary to transparency is taxation. While transparency legislation in the United States and Europe is a considerable advance, it does not necessarily put an end to tax evasion and tax avoidance. Companies that 


\section{Raymond Offenheiser}

engage in these practices generally under-value and under-report their levels of production and export value in order to decrease tax exposure in the exporting country. Then they take the profit from the sales of these commodities and move it through various offshore tax havens until it ends up in the one with the most favorable tax rates, thereby minimizing their tax exposure both in their country of origin and in the country where the company is headquartered. These practices bilk governments and citizens of billions of dollars that could be used for social programs, infrastructure, and productive investments in their home countries.

The release of the Panama Papers in 2016 provided a glimpse of the scale of these practices, but document only one firm in one tax haven (International Consortium of Investigative Journalists n.d.). It was the tip of the iceberg on tax evasion and avoidance. While governments have decried these practices and the OECD has sponsored a major initiative to address them, little has been done to shut down these tax havens. Important work is needed at the global level to confront this issue, change the way taxation is included in contract negotiations, reclaim the value of diverted funds, and reinvest them in development initiatives in their countries of origin.

Fiscal justice offers significant opportunities for building more accountable governance and promoting peace. Most peace accords involve the assurance of a more promising future for all parties. That requires financial investment. Funds lost to corruption, badly negotiated mining contracts, or tax evasion or avoidance represent an enormous missed opportunity. In many countries, the value of funds lost in this fashion dwarfs what is provided by donor governments in foreign aid or returned by companies in corporate social responsibility projects. Capturing this lost value and rechanneling it to development finance in poor communities where it originated could go a long way toward ensuring a more peaceful future.

\section{Peacebuilding and extractive industries: time for new strategies and tactics}

The triggers for mining-related conflict are complex, varied, and context specific, yet for the most part they have roots in individuals' and communities' sense that they have lost dignity and their ability to thrive economically and socially given the scale of disruption mining can unleash. Exercising their voice, they may first resist nonviolently, blocking a road or picketing a company office. If ignored, they may incite violence and wider conflict. Companies have historically looked to the state to intervene and neutralize the threat and defend their "right" to exploit, but increasingly today the use of coercive state power is seen within the industry as undermining the longterm viability of a project. They are now accountable to both shareholders and a new class of stakeholders who have invested in learning their business, imposing new norms, and demanding higher standards. In response, companies are seeking new ways to engage, gain legitimacy, and build trust. 
One of the places that road has led is the Vatican. Over the last several years, the Vatican has convened some five meetings on mining issues with CEOs of some of the world's largest corporations. The church, through its global reach, has also heard and convened scholars, activists, peacebuilders, and other representatives from communities affected negatively by mining and enabled them to present criticisms, grievances, and general recommendations for improvements. Companies have enormous financial, political, and social power because of their sheer size. They have used this power historically to secure rights and legislation that allow them to advance their interests, often at odds with the interests of local communities. Levelling the playing field between companies and local communities is a tall order. The church is one of the few institutions in the world that has the power to challenge extractive industries on an equal footing, pose thorny moral and ethical questions, and propose bold reforms in policy, practice, and institutional culture. It has exercised this moral authority on behalf of aggrieved mining communities at local and national levels, often with positive outcomes. While it has begun to engage extractive industries at the global level, it is still finding its voice and role and has not yet proven to be as effective as it could be.

In today's world, with the ever-growing demand for metals, minerals, and energy, it is probably unrealistic to assume that governments are going to forego mining revenue as they build their national economies. Outright denial of mining rights is rare. In most countries, a strong case must be made and backed by considerable public pressure to cancel a major project. If we must, therefore, live with some forms of extraction, how might peacebuilders maximize the Catholic community's potential to tame it? Traditional grassroots peacebuilding and human rights strategies alone will not be enough. New strategies, tactics, and alliances will be required that build upon the gains in norms and policy achieved over the last three decades. The following are some recommendations.

\section{Find allies with expertise}

One of the reasons the church has fallen short of being effective has to do with its lack of sophistication about many of the business, technical, legal, and financial issues specific to mining. Many recommendations are in areas in which the industry has already moved ahead and made significant investments in improvement. Church representatives are often unaware of many of these advances and may risk appearing uninformed about the strategic debates currently underway within the sector. Another reason is that the church has concentrated more on confronting the industry at the mine site level rather than at the corporate or policy level. In reality, many of the problems facing communities can be far more effectively addressed through policy, regulation, and proper government oversight. The goal of the church's important grassroots work should be to link grievances and 


\section{Raymond Offenheiser}

injustices at the community level to patterns of abuse at the national and global level and then turn the observation of these patterns into very specific policy recommendations to the industry at appropriate fora.

Oxfam's No Dirty Gold campaign has highlighted the importance of church leadership in Peru and El Salvador, and Publish What You Pay has pointed to the Catholic Church as a major partner in its efforts to increase transparency (van Oranje and Parham 2009, 36-37, 91-92). These examples show how dialogue and cooperation between civil society and the church can amplify the work of both for justice and peace in the mining sector.

\section{Integrate peacebuilding into international development}

Phil Vernon's (2015) report for International Alert provides a compelling analysis of how peacebuilding and economic development might benefit from a more integral relationship. Peacebuilders are generally seen by the development community as bystanders waiting for a conflict, rather than as partners on a common journey. Vernon's report claims that most conflict originates in some kind of economic challenge to the status quo that spins out of control. Therefore, effective development and peacebuilding require a sophisticated appreciation of local political economies, stakeholders, and their interests. Vernon argues that peace is best achieved when all parties to a conflict can find common ground and achieve an agreed-upon peace dividend. Peacebuilding that occurs in parallel or at odds with development actors is likely to fail or be perceived as marginal. The challenge for all advocates is to be clear about their complementarities in terms of knowledge, experience, competencies, and agendas. In the end, their shared interest is peace. Collaboration toward shared goals only empowers them both.

\section{Embrace sustainability as a peace principle}

Many mining companies have embraced sustainability as a principle driving future performance. They are attuned to the global focus on the Sustainable Development Goals; however, achieving real sustainability is an expensive challenge for mining companies. Mining requires major capital investments and access to abundant supplies of water and energy. Companies today recognize that in a world concerned with climate change and resource depletion, they must rethink their business models, invest in improved technology for environmental protection and cleanup, and assume greater responsibility for their impact on people and the land.

Environmental science within the industry has advanced dramatically over the last three decades. Peacebuilders would benefit from joining with environmentalists whose knowledge of these advances, and their shortcomings, could give them greater leverage with companies by providing the 
information needed to challenge company practices and governments' failures to hold companies accountable. Such protections for the environment could go a long way toward mitigating or preventing conflict between communities and companies as well as between communities who might otherwise experience rising tensions from resource scarcity. Mining will probably never achieve a perfect level of sustainability, but pressuring companies to adopt a shared-value approach and engage communities, governments, and stakeholders more transparently and proactively will push them to innovate and move in new directions. The Development Partner Initiative is an effort launched within the industry to foster precisely this kind of thinking, and peacebuilders should try to embrace and advance such efforts so that they become part of mainstream thinking. ${ }^{3}$

The logic of sustainability is central to Pope Francis's call to action in Laudato Si' which challenges individuals, governments, and businesses to work toward the creation of an economic order concerned with stewardship of the earth and dignity and integral human development for all humankind. Catholic actors can apply those ideas more effectively if they build off the present but imperfect industry-centered efforts toward sustainability. Doing so would also allow them to voice ideas like those from Laudato Si' that critique the technocratic paradigm that drives the mining industry and encourage changes and solutions that go beyond just technological innovation, such as supporting communities' right to say no to mining.

\section{Broaden the free, prior, and informed consent framework}

FPIC and transparency are perhaps the most powerful tools available to raise ethical questions and drive social change in the mining sector. The fact that ICMM has incorporated a free, prior, and informed consultation principle into their policy guidelines is progress, but insufficient progress. In much of the world, FPIC is still not a right recognized by governments or taken seriously by industry. Communities must be afforded the right to determine if the benefits of a mining project are worth sacrificing the investments their families have made in a region over generations. Peacebuilding groups should continue to press governments, investors, and civil society groups to not only support FPIC but enhance it. They should support and join efforts to legislate it at the national level and broaden the basis on which communities may assess risk by including not only environmental but other economic, livelihood, and human rights considerations. Communities should be given access to a due process review of any proposed project in an appropriate venue. FPIC is a normative framework that can rebalance relations in ways that may serve communities and avert unneeded division and conflict, but only if it is more deeply entrenched and more robustly developed and only if consultation becomes consent. The grassroots breadth of church actors combined with 


\section{Raymond Offenheiser}

the church's vertical reach to higher levels of authority, as well as its legitimacy and moral authority, give Catholic peacebuilders particularly strong capacity for effecting these sorts of changes if they can marshal it effectively.

\section{Push for improved transparency}

The situation is similar with transparency. A source of conflict in many mining regions is under-investment by both the state and private sector in the broader development of the region, creating the perception that the promised benefits of mining are never realized. The transparency reforms that have forced companies to report profits, royalties, and all other payments at the project level are enabling tax authorities to audit accounts more carefully and generate more revenue. They have also enabled citizens to influence legislatures to redirect some portion of previously generated tax revenue back to their region of origin. The Peruvian government had for years been holding millions of dollars of such funds in regionally designated accounts in its Central Bank because they felt regional governments lacked the capacity to manage these large sums. Now, as part of a national decentralization process, it has begun releasing those funds to the regions to underwrite a variety of public services and infrastructure projects. And Burkina Faso has now legislated that one percent of annual revenue from gold mining be reinvested in mining communities. That may seem low, but this is a major source of tax revenue for a poor country, and it's a start. The precedent matters and allows regional governments to press for disbursements and challenge for increases in the future. This is a space where investments need to be made by governments and companies in building local governing capacity to support local management of such large sums.

Making the flow of this capital visible enables civil society actors to press for fiscal justice for communities through a proportionate share of revenue in equitable and sustainable development for their regions. But in many cases this information is not put to effective use. If contracts are not made more equitable, and taxes paid and allotted fairly, then any sins revealed by transparency initiatives pass without accountability. Leveraging that information to encourage investment planning in the early phase of project development may have the important indirect effect of minimizing future tension and conflict aggravated by economic hardships. While such fiscal policy work may seem tangential to traditional peacebuilding and human rights work, it is necessary to give tools like FPIC and transparency real weight.

\section{Demand hard law when soft law fails}

While some countries have binding laws on transparency and FPIC, for the most part companies are only governed by voluntary compliance frameworks. 
Hence, company response has been uneven. For these mechanisms to be as effective as they can be for building peace and justice, they need to be written into legislation and actually enforced. As noted above with regard to FPIC, the vertical reach of the Catholic community gives it particular capacity for policy advocacy that connects community-level experiences and needs with regulatory and legislative bodies. This is not a domain in which many in the peacebuilding or broader activist community have been active. Yet it could be fruitful for such groups to focus some of their energies here in the future.

\section{Conclusion}

The mining sector is large and complex, as are the issues that surround it. The sector is changing, albeit under pressure. Leading companies are looking for advice and allies to help it change in the right ways. Engaging this momentum for change in a productive way is a unique opportunity for Catholic peacebuilders. What must be done to use it successfully?

To begin, peacebuilders and human rights advocates must begin to think outside their comfort zone and become educated about the sector, its history, culture, operations, financing, politics, and risks. Success in driving change will depend in large measure on the ability to be a challenging advocate with a strong moral narrative, an evidence-based critique, and technically and financially sophisticated propositions for reform. It will also require finding allies within the industry to begin and sustain dialogue, even as strong, credible, yet constructive critics.

The moral authority of the church represents a very significant brand and reputational risk to mining firms. Through its global presence, the Catholic Church is very often on the frontlines in mining conflicts. Industry leaders recognize the influence of the church on political leaders across the world, which explains why they have attended five meetings at the Vatican. Going forward, the church has to present a much more unified and effective front to industry. It must find ways to transform the multiple grievances it hears from its grassroots constituents into a coherent agenda of proposals to present to industry leaders. It must invest in building an internal structure that allows it to operate coherently on the local, national, and global levels. It must assemble a community of diverse advisors with deep understanding of the financial, technical, and operational aspects of the industry to assist in formulating its proposals and representing its views in formal sessions. It must develop an agenda of issues that are priorities for reform at the local, national, and industry levels and make common cause with the leading international NGOs and civil society organizations that have a long track record of commitment and achievement in this sector. It must give serious consideration to how it might use its powerful moral and ethical voice in support of the cutting-edge reform agendas currently on the table that hold the most promise of success. Its secular partners 


\section{Raymond Offenheiser}

can provide excellent counsel on the opportunities, complexities, and politics surrounding each of these issues.

The good news is that the mining industry knows that it has to do better. Its past history of exploitation and abuse is a legacy liability in the twenty-first century. It must reinvent itself in order to survive operationally and financially. It is beginning to invest in research and development of new technologies. The more enlightened firms have embraced principles of sustainability, shared value, stakeholder consultation, and human rights and are trying to figure out how to include these ideas in their multi-year strategic and operational plans. Others are embracing a mindset shift toward becoming fully engaged development partners-moving from thinking narrowly inside the fence to thinking broadly outside the fence.

These are trends that, if harnessed, bode well for change that can benefit millions of people in countries in which mining is the dominant industry. The church and its field-based peacebuilders hold the potential to bring a moral framework to these industry reflections that could enrich the lives of millions, reduce corruption and conflict, and advance sustainability across the globe.

\section{Notes}

1 Majors include such companies as Anglo American, AngloGold Ashanti, Glencore, Newont, Rio Tinto, Valle, BHP, et al.

2 See https://eiti.org.

3 See http://www.dpimining.org.

\section{References}

Australian Associated Press. 2019. "BHP and Rio Tinto Join Push for Indigenous Voice to Parliament." The Guardian, January 30, 2019. https://www.theguardian.com/ australia-news/2019/jan/31/bhp-and-rio-tinto-to-join-push-for-indigenous-voice-toparliament.

International Consortium of Investigative Journalists. n.d. "The Panama Papers: Exposing the Rogue Offshore Finance Industry." Accessed March 22, 2021. https://www.icij.org/investigations/panama-papers.

International Council of Mining and Metals. n.d.a. "Indigenous People and Mining." Accessed March 22, 2021. http:/www.icmm.com/en-gb/members/ member-requirements/position-statements/indigenous-peoples.

International Council of Mining and Metals. n.d.b. "Mining Principles." Accessed March 22, 2021. https://www.icmm.com/en-gb/members/member-requirements/ mining-principles.

Porter, Michael, and Mark R. Kramer. 2001. "Creating Shared Value.” Harvard Business Review. https://hbr.org/2011/01/the-big-idea-creating-shared-value.

Russell, Grahame. 2019. "Es posible alcanzar la justicia en Canadá o en Guatemala por la represión vinculada a la minería de Hudbay Minerals/CGN?" Rights Action. July 23, 2019. https://mailchi.mp/rightsaction/es-posible-alcanzar-lajusticia-en-canad-o-en-guatemala-por-la-represin-vinculada-a-la-minera-dehudbay-mineralscgn. 
US Geological Survey. n.d. National Minerals Information Center. Minerals Yearbook: Volume I -Metals and Minerals. Accessed March 22, 2021. https:// www.usgs.gov/centers/nmic/minerals-yearbook-metals-and-minerals.

van Oranje, Mabel, and Henry Parham. 2009. Publishing What We Learned: An Assessment of the Publish What You Pay Coalition. London: Publish What You Pay. https://eiti.org/files/documents/Publishing\%20What\%20We\%20Learned.pdf. Vernon, Phil. 2015. Peace Through Prosperity: Integrating Peacebuiding Into Economic Development. London: International Alert. https://www.internationalalert.org/publications/peace-through-prosperity.

World Bank. 2003. Striking a Better Balance: Volume 1. The World Bank Group and Extractive Industries. Washington, DC: World Bank. https://openknowledge. worldbank.org/handle/10986/17705.

World Economic Forum and Global Agenda Council on the Future of Mining and Metals. 2015. "Voluntary Responsible Mining Initiatives: A Review." White Paper. World Economic Forum and Resolve Solutions Network. http://www3. weforum.org/docs/Voluntary_Responsible_Mining_Initiatives_2016.pdf. 